\title{
Chains of securitization
}

\section{Marieke de Goede}

University of Amsterdam, Netherlands

\section{Financial security: A new field of study?}

Recent years have seen welcome growth in the exploration of the philosophical, conceptual and practical interrelations between 'finance' on the one hand, and 'security' on the other. While we are presently accustomed to seeing finance and security as quite different epistemological traditions and practical domains, a historical reading reveals their conceptual and empirical twinning. Security and finance are both modern strategies and technologies of dealing with the uncertain future. The histories of colonial conquest and financial innovation are jointly premised on novel time horizons that stretched the future beyond the boundaries thinkable in the Middle Ages (Campbell and Dillon, 1993: 6-7; Leyshon and Thrift, 1997). Jointstock companies - such as the Dutch East India Company - were not simply vehicles for financial investment and new modes of risk-taking, but were also authorized to act in the name of the national state. They established forts and settlements, monopolized trade routes and combated colonial competitors (Burch, 1998: 107-35). In this sense, finance and sovereignty have been historically co-constitutive. The risk instruments that elicited early modern investment and that financed voyages of exploration, simultaneously made possible colonialization on a novel scale, as well as the securitization of trade routes and the high seas.

The conceptual and empirical affinity of finance and security has now become recognized to the extent that we can say it has led to a modest but vibrant new research field under the broad heading of 'financial security' (for example, see Boy, Burgess and Leander, 2011; Aitken, 2011; Amicelle, 2011; de Goede, 2010; Gilbert, 2015a; 2015b; Langenohl, 2017; Lagerwaard 2015; Langley, 2014; Lobo-Guerrero, 2016). In his contribution to this forum, Paul Langley (2017: 175) speaks about the configuration of finance/security/life, suggesting we analyze the various ways in which financial markets "come to figure in governance that securitizes a valued, neoliberal form of life". With this formulation, Langley shows the broad stakes of analyzing finance-security interrelations. The promise of 'financial security' as a research field is its ability to further a dialogue between what are now commonly understood to be different sub-fields of international politics, including International Political Economy (IPE), International Political Sociology (IPS) and Critical Security Studies (CSS). Though some fruitful conversations have started to take place - not least in the pages of Finance and Society - much is to be gained by challenging the disciplinary division between IPE, IPS and CSS. An empirical focus

\section{Corresponding author:}

Marieke de Goede, Department of Political Science, University of Amsterdam, Amsterdam, Netherlands.

Email: m.degoede@uva.nl 
on finance/security comprises broad attentiveness to, for example, technologies of governing, the importance of temporality and (un)certainties, and the profound interrelations of commerce and security. Even though my own background was in IPE, studying financial speculation quickly revealed that the history of finance is replete with questions of security: from the contestations over speculation as an instrument of (in)security, to the question of securing livelihoods for farmers and investors, to the significant role that the financial industry acquired in suspicious transactions monitoring after 9/11 (de Goede 2005; 2012).

In the context of this emerging field of study, the dual meaning of securitization has been frequently noted but remains underexplored (but see Kessler, 2011; Langenohl, 2017). On the one hand, in political economy debates, securitization refers to the technical financial process whereby objects or financial assets are repackaged and marketed to constitute investment vehicles. Securitization, in this sense, is often critiqued for detaching the financial economy from its underlying 'real' products and transactions, and fostering financialized, neoliberal, economies (as in Montgomerie and Williams, 2009). On the other hand, securitization is a term that has become widely used to describe the process whereby societal issues and phenomena come to be understood as security threats (Buzan et al.,1998; Williams, 2003, Hansen, 2006; Waever, 2011). This conceptualization starts from the premise that security threats do not exist independently from discursive mediation and subjective processes of meaning-making (also Campbell, 1992). While quite different in origin and ontology, however, in both senses the term securitization refers to a process by which phenomena are rendered into securities. As Nina Boy (2015: 530) has suggested, securitization in its dual meaning refers to the process of "making liquid, making credible and making plausible".

According to Boy, Burgess, and Leander (2011: 116), the disciplinary separation of "studies of finance and studies of sovereignty" generates a research "blind spot". This means that the constitutive importance of public credit to the founding of the modern state and the practice of state security is often overlooked. Other themes like the dual meaning of securitization, the deployment of money as a 'weapon of war' (Gilbert, 2015a; 2015b), or the security role of financial institutions (Amicelle, 2011; Amicelle and Faravel-Garrigues, 2012; de Goede, 2012) have similarly received limited attention. In carving out space for a research agenda on financial security, Boy et al. (2011: 118) specifically call for attention to the material practices that (re)produce specific forms of finance/security governance because, "so far, studies of the practices ... at the interstice finance/security - have been few and far between". My contribution to this forum discussion heeds the call for such attentiveness to practice in its exploration of the dual meaning of securitization. It seeks to develop the notion of 'chains of securitization' as a concrete, practice-based, way to analyze how uncertain futures are parcelled up, packaged, rendered mobile, credible and liquid.

\section{The double meaning of securitization}

I have previously argued that the interrelation between finance and security is most apparent in its conceptual doubling and its shared rationality (de Goede, 2010, reprinted in this Forum). As Randy Martin (2007: 17) has astutely observed, "pressing on the political meaning of security" inevitably brings "its economic double to the surface". Indeed, interrogating the historical and conceptual meanings of finance on the one hand, and security on the other, reveals their profound entanglement. Both are modern strategies of dealing with the uncertain future. If the vicissitudes of life and the fickleness of fortunes were ascribed to God and fate in the pre-modern era, finance and security are distinctly modern strategies of anticipating and 
strategizing. The two domains have a shared history in the invention of risk and the calculation of probability as ways of rendering the unknown future calculable and knowable (Daston, 1988; Hacking, 1990). The invention of risk as a calculable entity was crucial to the emergence of financial markets, their domineering growth in the twentieth century, as well as their political defence and moral articulation (Amoore, 2004; de Goede, 2005). Risk is also central to modern practices of security, which, according to Foucault (2007: 59), entail a "rationalization of chance and probabilities".

Securitization similarly has a dual rationality, which twins a financial sense to one of modern statecraft and national security. In both senses, securitization refers to the process whereby an object, asset or phenomenon is rendered into security. In the case of financial securitization, the referenced objects or assets that are securitized in order to become investment products have varied widely historically: from tulips not-yet-in-bloom, to wheat stocks, to pools of household mortgages. As Leyshon and Thrift (2007) have argued, financial securitization has the capacity to render virtually anything into a security that forms the basis of financial investment. As a contemporary well-known example, mortgage securitization involves the bundling and repackaging of countless mundane mortgage payments, which are rendered liquid as global investment opportunities. In this manner, future financial flows are rendered into a security - understood as a tradeable property or pledge (OED, 5a). In parallel, the referenced objects of securitization, understood as rendering-into-threat, have also varied greatly throughout history. They commonly include borders and migration (Huysmans, 2006), but may also constitute themselves in relation to race, gender, history, political ideology, and so on. As David Campbell (1992) has shown, security threats are constructed through a process of 'writing difference,' whereby the Self is constituted with reference to a dangerous, unruly, Other. Securitization understood as a discursive process thus has the capacity to render a wide - and in theory, unlimited - range of phenomena into security issues, which, in turn provide the basis for considerable commercial investments and opportunities (on this see Hoijtink, 2014).

The entanglement of finance and security depends not purely on rationalities of risk, but even more so on the institutional processes and practices that bring the future within present grasp in particular ways (Mitchell, 2014). Both modes of securitization involve discursive, technical and professional practices. Though initially the International Relations (IR) literatures on securitization emphasized the primacy of the speech act, we increasingly see analyses of the professional, bureaucratic and dispersed practices and technical artefacts of enacting security (Huysmans, 2011; Amicelle et al., 2015). In parallel, a rich body of literature broadly in the domain of the social studies of finance unpacks the practical, epistemological and technological work of financial securitization (MacKenzie, 2007; Lange, 2016). However, a cross-fertilization, whereby the conceptual toolbox of IR scholarship on securitization is made relevant to the study of financial processes, and whereby the conceptual toolbox of the social studies of finance, in turn, is made relevant to the study of state security practices, is still lacking (but see Boy, 2015 and Langenohl, 2017 for pioneering work).

Moreover, observations regarding the dual rationality of securitization still say little about the precise ways in which finance and security render uncertain futures mobile, liquid and anticipated. On the one hand, we do not want to entirely conflate finance and security, if only because - despite their conceptual affinity - their practical domains were separated historically, to the extent that they now largely have their own laws, habits, and literatures. On the other hand, observing a shared rationality does not yet reveal enough about the processes and practices that concretely securitize. Sven Opitz and Ute Tellmann (2014: 109) have drawn attention to the "diverse processes of future-making" that function differently across social 
orders. They differentiate specific modes of future-making across law, security and finance. In their reading the security imaginary is distinct, in the sense that it entails an "act of defuturization": "It does not stretch out before us like an open field, but it comes at us. It is a future not to be lived but to be survived" (Opitz and Tellmann, 2014: 112, emphasis in original). Financial futures, on the other hand, trade on openness and volatility, until a fixed reference point. They monetize ways of keeping options open; they entail a "peculiar temporality that fixes a future point in time and links it to a horizon of high volatility until then. Everything is utterly uncertain until that future fix point" (Opitz and Tellmann, 2014: 115; see also Tellmann, 2018). In short, Opitz and Tellmann start unpacking the distinctive practices of futurity in the social orders of finance, emergency and law. They demonstrate that the politics of time may take many different shapes to parcel, package, trade on, or anticipate the uncertain future.

\section{Chains of securitization}

Building on these insights, I argue that it is fruitful to understand different modes of securitization as chains of translation. For Bruno Latour (1999), a chain of translation is the set of practices through which scientific facts are produced. This entails not the immediacy of objective scientific discovery, but an iterative process of collecting, inscribing, moving and classifying. I suggest that this understanding offers viable conceptual tools to examine in some detail how the future is rendered knowable, plausible, and liquid in finance/security. My suggestion is that we can follow the contingent processes through which the (de)futuritizations discussed by Optiz and Tellman are imagined, built, and made to function.

Others have already used the notion of a 'value chain' or 'wealth chain' to analyze the processes through which dispersed and distributed corporate networks operate. These approaches draw attention to the fragmentation and "disaggregation of production processes across space" (Seabrooke and Wigan, 2017: 4). Seabrooke and Wigan develop the notion of 'global wealth chains' to analyze the legal, financial and jurisdictional aspects of globally dispersed production networks. Tracing global wealth chains makes it possible to unpack how these "hide, obscure, and relocate wealth in a manner that breaks from the location of value creation and heightens inequality" (Seabrooke and Wigan, 2017: 4). By comparison, Arjaliès et al. (2017: 4) speak about "chains of finance" when analyzing the "sequence of intermediaries" that underpin contemporary globalized finance. They focus on the social entities ('savers', 'pension funds', 'insurance companies' and so on) that mediate and obscure the relation between investor and supplier. Taken together, these approaches show the merit of chain-like metaphors when analyzing complex financial practices (contra Erturk et al., 2011).

However, a Latourian approach pushes further: beyond a focus on interconnected social entities, to focus more squarely on processes of materialization and translation. The Latourian chain, then, differs fundamentally from existing notions of wealth chains. Through this lens the question becomes: How do objects of uncertainty materialize through sequenced and iterative chain-like processes of translation and reference? The aim would be to follow the particular ways in which 'pieces' of the unknown future are carved off, packaged, sold, moved, reported, and acted on. In Pandora's Hope, Latour (1999) joins the Amazonian expedition of a group of soil scientists, who identify, collect, analyze, sample and classify soil samples with the broad goal of scientific discovery concerning the state of the Amazonian forest. Latour follows the soil sample's path from the depths of the Amazonian forest to its function as piece of evidence in the Parisian laboratory. Latour's chains of translation involve an iterative process, crossing 
many small gaps of interpretation, involving a 'dialectic of gain and loss' (I develop this argument in more detail in de Goede, 2018).

We can appropriate Latour's concepts in order to follow the complex processes by which the future is carved off and parcelled up. How does the future materialize as an object that can be bought and sold, or reported and shared? Such an object-centered focus, I think, brings another kind of politics into focus. John Allen and Michael Pryke (2013) offer an example of how this might work in their compelling analysis of the financialization of the Thames Water company. Allen and Pryke (2013: 434) show that future payments of Thames Water customers until the year 2062 were anticipated, packaged and made liquid. The maturity dates of the bonds that bundle, package and sell the future payments streams of household water bills stretch fifty years before us. The future materializes as a specific object of risk that is rendered tradeable in the present. Such present liquidity relies not just on specific rationalities of calculation and commensuration, but also on "an extended network of brokering arrangements" (Allen and Pryke, 2013: 423). This network is akin to Latour's action at-a-distance, in the sense that it does more than link deals in the marketplace, but also translates what is being brokered, generating a "flattened topography" (Pryke and Allen, 2017: 16). In this sense, Allen and Pryke move beyond the understanding of the network-like social structures needed for financial securitization, in order to foreground the material politics of translation that render mundane household water bills into global speculative vehicles.

Through sequencing and movement, objects of uncertainty materialize as investments both in the financial sense of risk-based speculative products, and in the sovereign sense of opportunities for disruption or targeting. A chain of securitization is not necessarily a linear sequenced path (Erturk et al., 2011), but can better be thought of as a recursive trajectory. Such a trajectory can be "indirect, devious, mediated ... vascularized" (Latour, 1999: 174). A chain can be looped, doubled, bended or kinked. The value of thinking in terms of the mechanics and material properties of a chain, however, is that it draws attention to the relatively regulated sequences of interpretation, iteration and movement that render objects emergent. For Latour, each sequence in the process refers back to a prior object; each step of selection and inscription form the basis of the next move of the scientists. In this sense, translation is both emergent and sequenced: as Andreas Langenohl (2014: 94) has pointed out, "adequacy" in translation "can never be vouched for", yet the question of adequacy "remains valid all the same".

The object of securitization (in the dual sense of a future financial flow and a future threat) does not pre-exist the chain of reference, nor does it remain stable throughout. As Allen and Pryke show, the object of uncertainty moves, morphs and modulates, as it passes from one stage of the chain to the next (and back again). As Stritzel (2011: 344) has also put it, "translation ... does not just 'transport' meaning, but also creatively produces it, it rewrites, rearticulates, re-represents something in new terms" (emphasis added). Following these movements and translations helps grasp the politics of securitization. This approach has the capacity to unpack the many small gaps of understanding that need to be crossed to render the future liquid.

This short forum piece does not allow for a full empirical illustration of how chains of securitization may work as a conceptual approach and methodological tool. Instead, let me just give two brief examples that can help illustrate my purpose. Figure 1 represents the network of securitization that created and sold the ABACUS-2007-AC1 mortgage-backed Collateral Debt Obligation (CDO). ABACUS-2007-AC1 became infamous as one of the 'toxic' CDOs that helped precipitate the 2008 financial crisis. ${ }^{1}$ One of the reasons we know quite a lot about ABACUS, and how it was constructed and marketed, is because it was a key figure in the 
civil trial of Goldman Sachs employee Fabrice Tourre, who after the crisis became indicted for investment fraud and knowingly misleading clients.

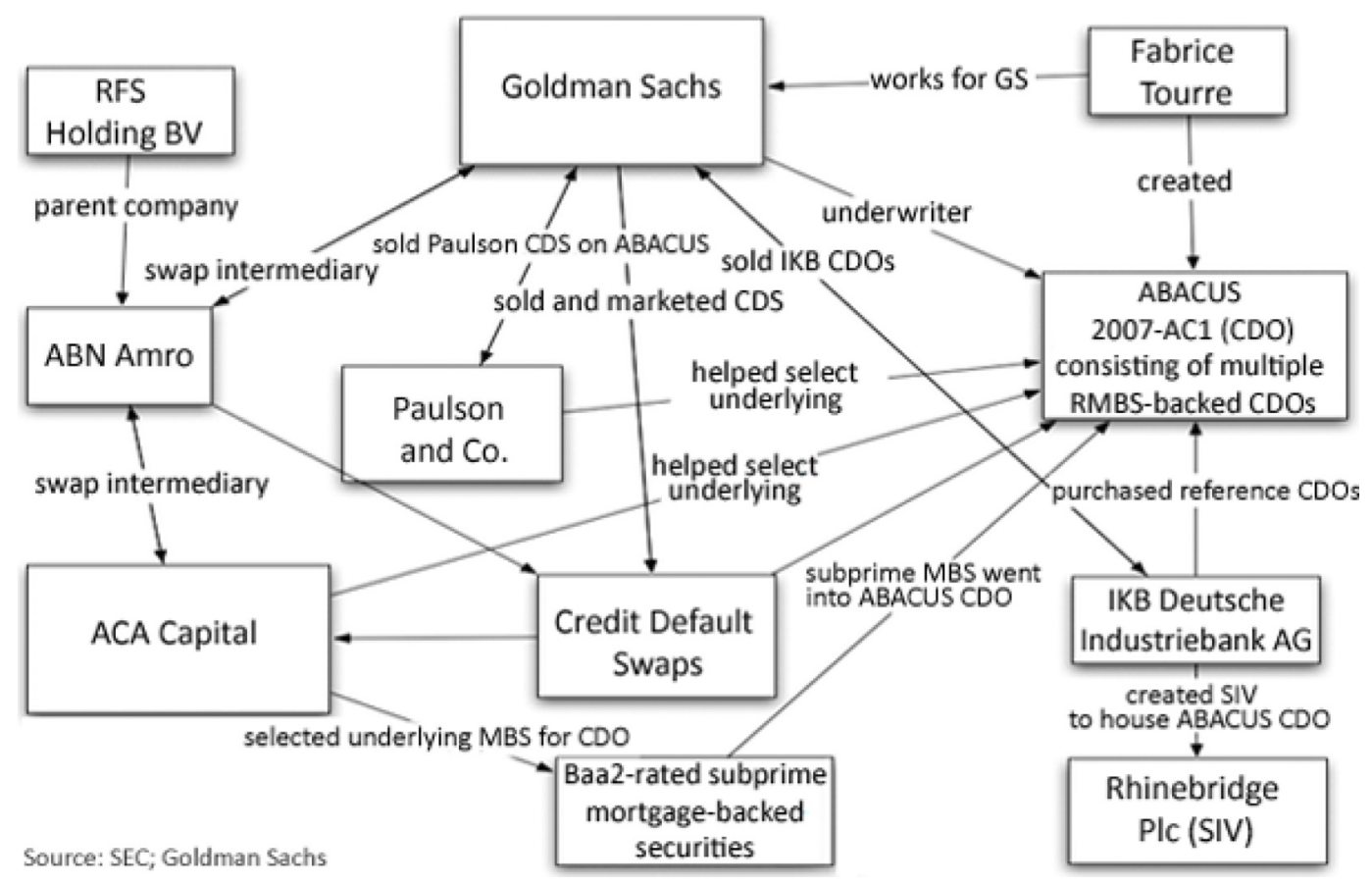

Figure 1. ABACUS-2007-AC1. Source: Clusterstock Chart of the Day [Business Insider, 20 April 2010].

If we approach Figure 1 as a chain of securitization, we can follow the work of future-making that is central to the creation of this speculative vehicle. The uncertain future that is carved off, referenced and commodified in ABACUS can be found in the bottom middle of the Figure as sets of 'Baa2-rated subprime mortgage backed securities'. These securities bundle and commodify the future payment streams of hundreds of individual US subprime mortgages, issued by Wells Fargo and other mortgage lenders. The future pay-off dates of these mortgages (traded in 2006) were typically 2035 and 2036, stretching the work of futuremaking for about thirty years. ${ }^{2}$ The distributed uncertainties of the individual, sub-prime, mortgage payments, become pooled into new securities, with their own risk grade. Those Baa2-rated securities, in turn, are referred to (thus: referenced but not traded) in a new collective object called ABACUS-2007-AC1. ABACUS was a so-called synthetic CDO that allowed speculators to gamble on the performance of the referenced assets. Formally, it provides insurance against losses and defaults of those mortgage pools, though they were widely used as speculative vehicles on the performance of the mortgage loans, without purchasing or trading the underlying securities (or under-underlying mortgages).

ABACUS-2007-AC1 as an investment product is pictured in the middle right of Figure 1. It repackaged and translated the many uncertainties of the household mortgage payments into one investment vehicle that does not speak of the household mortgages anymore at all. The object of uncertainty has morphed, so that the marketing materials of ABACUS speak of ninety 'Reference Obligations' (meaning, the referenced mortgage pools). The credibility and plausibility of ABACUS as an investment are cast in terms of the reference obligations being static, fully disclosed, and diversified in terms of mortgage providers (with the largest servicer, Wells Fargo, representing $29 \%$ of the Reference Portfolio). ${ }^{3}$ The marketing materials further 
emphasize the credibility of the firm that helps 'select' the referenced mortgage pools - ACA Capital (bottom left in the Figure 1) - and notes the size of ACA's CDO portfolio (US\$15,7 billion). The object of uncertainty is translated here, from the manifold uncertainties associated with the individual future mortgage payments, to the risk assessment of the 90 mortgage pools that are diversified in terms of the underlying securities issuers and the referenced mortgage companies. ABACUS itself of course has a much shorter future fix-point than the thirty year stretch of the referenced mortgages, requiring annual settlements, and subject to aggressive marketing that promised the possibility of high short-term gains (by $\mathrm{Mr}$ Fabrice Tourre, a mid-level marketing manager, pictured top right). Here, the object of uncertainty undergoes a further translation to be understood as a unique and limited opportunity, with so-called investment grade quality and the possibility of high yields (Lewis, 2011).

My point here is not to retell the whole complex story of the construction of ABACUS, its failure and juridical controversy (for part of that story, see de Goede, 2015). The point is to illustrate how we might follow a chain of securitization, which makes it possible to analyze how an object of uncertainty materializes as an investment opportunity, and how it is further translated, referenced and packaged. This particular chain produced spectacular insecurity: within one year, 99\% of the ABACUS portfolio had been downgraded, and investors lost over $\$ 1$ billion (while others, who had gambled on the crash of the mortgage security markets, profited). Tourre himself was indicted for fraud and found guilty of misleading investors. ${ }^{4}$ Tourre's trial understood ABACUS as a product that was 'destined to fail'. In contrast, understanding ABACUS and similar instruments as enabled through a chain of securitization would emphasize its emergent properties, recognizing that its 'failure' or 'success' is situated, and dependent on socio-material conditions. In other words, the boundaries of illegitimate and legitimate financial trading can only be drawn in retrospect - and many mid-level financial professionals, who operated at the limits of law when designing novel financial products, escaped Tourre's fate.

In parallel, we could follow the materialization of the uncertain future as an opportunity for security intervention and disruption in relation to counter-terrorism practices. As I have suggested elsewhere, here we can trace the trajectory of a suspicious financial transaction along a chain of detection, reporting and investigation. For example, banks and wire transfer companies have started mining their databases for ATM transactions at the Turkish-Syria border. They identify, select and report particular transactions that are considered to be abnormal and possibly related to support for the armed battle in Syria. Banks' datamining and reporting practices, then, translate selected mundane transactions from routine ATM withdrawals or wire transfers into indicators of potential support for the Syria conflict. Such reported transactions may become leads for police and grounds for criminal investigation and arrest. In a further translation, such a transaction may (sometimes) become an indicator of terrorist intent before a court of law, especially now that European courts are increasingly faced with criminal prosecution of cases relating to travel to Syria. Throughout this chain, transactions data are translated: they move and morph, they are rendered recombinable with other data(sets), and acquire different meanings and capacities. Though not many suspicious transactions eventually come to function as court evidence, they become powerful when they do so (as in the case of the conviction of a 28-year-old Dutch citizen to two years imprisonment for terrorism financing, on the basis of monies sent to his brother believed to be in Islamic State-held territory). ${ }^{5}$

Though this example is very different from ABACUS, my suggestion is that here too, we can observe the materialization and translation of a particular object of uncertainty. Amid a 
multitude of mundane quotidian wire transfers and the generalized dangers of terrorism, a particular transaction becomes identified and singled out, reported and moved. At each link in this chain of securitization, a wire transfer transaction becomes read differently, and is inscribed with particular security meanings. From a routine wire transfer to Turkey, it becomes inscribed with the potential to support the violence and terrorism of Islamic State. In a further translation, the wire transfer becomes part of a police investigation and subsequent prosecution. At each stage in this chain of translation, there are gaps of understanding and interpretation that need to be crossed; at each stage in the chain, there are politics at work. The overall effect of this chain of securitization is to produce opportunities for investigation, policing and prosecution. This is materially different from ABACUS, the overall purpose of which is to enable global speculation and incur fees. Nevertheless, both examples entail processes of securitization - in its dual sense - whereby emergent futures become rendered liquid, credible and plausible (Boy, 2015), enabling present investments.

\section{Concluding: Politics/chains}

In my contribution to this forum I have advanced the notion of 'chains of securitization', arguing that this concept helps researchers to focus on the materialization and translation of particular understandings of the future. I have explored the examples of complex derivatives, in parallel to the materialization of a suspicious transaction in a chain of financial reporting and investigation. Despite their differences, both chains discussed here involve materiallyembedded ways of carving off uncertain futures, packaging them in specific ways, and rendering them recombinable with other transactions. Both involve complex institutional chains of reference, referral and iteration. The chain-like metaphor draws attention to the relatively regulated processes of sequencing and movement that allow objects of (in)security to emerge. Translation is contingent and emergent, but it is not fully arbitrary, as it needs to continuously refer back to prior steps and previous movements in the chain.

By drawing this parallel, my broad aim is to offer ways of studying finance/security as more than a shared historical rationality, but also as a dispersed practice that progressively inscribes uncertain futures into material investment products and security workflows. It seeks to offer concrete (i.e., methodological) tools to unpack how (de)futurization is enacted, packaged, sold, reported, translated and made actionable as security/financial investments. The suggestion is that focusing on concrete materializations may challenge the disciplinary boundaries between IPE, IPS and CSS. It offers one avenue for moving away from a priori disciplinary divisions whereby, for example, certain questions are assigned to the concepts and methods of IPE, while others are assigned to the concepts and methods of CSS. Instead, the suggestion is to start with the object, and deploy concept and tools as warranted by the empirical terrain. This will allow us to focus more pragmatically on how 'financial' objects, such as derivatives, are assembled to generate (in)securities; or how 'security' objects, such as suspicious transactions, are assembled across public/private domains.

Both chains discussed in this contribution ultimately enable important security investments and decisions. Both require crossing countless gaps of understanding, which is where the politics of securitization are located. An object-centered approach does not seek to evacuate social contestation from our understandings of finance/security. On the contrary, in the tradition of ANT, it seeks to multiply the places and moments at which we can observe contestation. The politics of securitization are dispersed throughout the chain of sequencing, translation and referral. They are located in the many small gaps of understanding that need to be crossed at each link in the chain. 


\section{Acknowledgments}

Sincere thanks to Nina Boy, Nathan Coombs, Amin Samman, and the guest editors of Finance and Society for bringing this forum section together and developing financial security as an interdisciplinary research field. Financial support for this research is provided through the European Research Council (ERC-2015-CoG 682317: FOLLOW).

\section{Notes}

1. For the culture of mortgage securitization in the context of the financial crisis, see Langley (2008); for the valuation practices of mortgage securities and CDOs, see MacKenzie (2011); for a readable (but somewhat problematic) account of mortgage securitization and CDOs, see Lewis (2011).

2. The set of referenced MBSs in ABACUS can be found at: <https://www.math.nyu.edu/faculty/avellane/ABACUS.pdf>. See slides 56 and 57.

3. From the marketing materials, slide 13: <https://www.math.nyu.edu/faculty/avellane/ABACUS.pdf $>$.

4. The Securities and Exchange Commission indictment of April 16, 2010, is available at: <https://www.sec.gov/litigation/complaints/2010/comp-pr2010-59.pdf>.

5. I discuss this case in more detail in de Goede (2018).

\section{References}

Aitken, R. (2011) Financializing security: Political prediction markets and the commodification of security. Security Dialogue, 42(2): 123-41.

Allen, J. and Pryke, M. (2013) Financialising household water: Thames Water, MEIF, and 'ring-fenced' politics. Cambridge Journal of Regions, Economy and Society, 6(3): 419-39.

Amicelle, A. (2011) Towards a new political economy of financial surveillance. Security Dialogue, 42(2): 161-78.

Amicelle, A. and Faravel-Garrigues, G. (2012) Financial surveillance: Who cares? Journal of Cultural Economy, 5(1): 105-214

Amicelle, A., Aradau, C. and Jeandesboz, J. (2015) Questioning security devices: Performativity, resistance, politics. Security Dialogue, 46(4): 293-306.

Amoore, L. (2004) Risk, reward and discipline at work. Economy and Society, 33(2): 174-96.

Arjaliès, D.-L., Grant, P., Hardie, I., MacKenzie, D. and Svetlova, S. (2017) Chains of Finance: How Investment Management is Shaped. Oxford: Oxford University Press.

Boy, N. (2015) Sovereign safety. Security Dialogue, 46(6): 530-47.

Boy, N., J. Burgess, J.P. and Leander, A. (2011) The global governance of security and finance. Security Dialogue, 42(2): 115-22.

Burch, K. (1998) 'Property' and the Making of the International System. Boulder, CO: Lynne Rienner.

Buzan, B., Waever, O. and de Wilde, J. (1998) Security: A New Framework for Analysis. Boulder CO:

Lynne Rienner.

Campbell, D. (1992) Writing Security. Minneapolis, MN: University of Minnesota Press.

Campbell, D. and Dillon, M. (1993) The end of philosophy and the end of International Relations. In:

Campbell, D. and Dillon, M. (eds.) The Political Subject of Violence. Manchester: Manchester University Press, 1-47.

Daston, L. (1988) Classical Probability in the Enlightenment. Princeton, NJ: Princeton University Press. de Goede, M. (2010) Financial security. In: Burgess, J.P. (ed.) The Routledge Handbook of New Security Studies. London: Routledge, 100-109. 
de Goede, M. (2012) Speculative Security: The Politics of Pursuing Terrorist Monies. Minneapolis, MN:

University of Minnesota Press.

de Goede, M. (2015) Speculative values and courtroom contestations. South Atlantic Quarterly, 114(2):

355-75.

de Goede, M. (2018) The chain of security. Review of International Studies, 44(1): 24-42.

Erturk, I., Froud, J., Leaver, A. and Williams, K. (2011) Changing the metaphor: Finance as circuit. SocioEconomic Review, 9(2): 580-88.

Foucault, M. (2007) Security, Territory, Population: Lectures at the Collège de France, 1977-1978.

Transl. by Graham Burchell. Basingstoke: Palgrave.

Gilbert, E. (2015a) Money as a 'weapons system' and the entrepreneurial way of war. Critical Military

Studies, 1(3): 202-19.

Gilbert, E. (2015b) The gift of war: Cash, counterinsurgency and 'collateral damage'. Security Dialogue,

46(5): 403-21.

Hacking, I. (1990) The Taming of Chance. Cambridge: Cambridge University Press.

Hansen, L. (2006) Security as Practice. London: Routledge.

Hoijtink, M. (2014) Capitalizing on emergence: The 'new' civil security market in Europe. Security Dialogue, 45(5): 458-75.

Huysmans, J (2006) The Politics of Insecurity: Fear, Migration and Asylum in the EU. London:

Routledge.

Huysmans, J. (2011) What's in an act. Security Dialogue, 42(4-5): 371-83.

Kessler, O. (2011) Beyond sectors, before the world: Finance, security and risk. Security Dialogue, 42(2): 197-215.

Lagerwaard, P. (2015) Negotiating global finance: Trading on Dalal Street. Journal of Cultural Economy, 8(5): 564-81.

Lange, A.-C. (2016) Organizational ignorance: An ethnographic study of high-frequency trading.

Economy and Society, 42(2): 230-50.

Langenohl, A. (2014) Scenes of encounter. In: Bachmann-Medick, D. (ed.) The Trans/National Study of Culture: A Translational Perspective. Berlin: De Gruyter, 93-117.

Langenohl, A. (2017) Securities markets and political securitization: The case of the sovereign debt crisis in the Eurozone. Security Dialogue, 48(2): 131-48.

Langley, P. (2014) Liquidity Lost: The Governance of the Global Financial Crisis. Oxford: Oxford University Press.

Langley, P. (2017) Finance/security/life. Finance and Society, 3(2): 173-79.

Latour, B. (1999) Pandora's Hope: Essays on the Reality of Science Studies. Cambridge MA: Harvard University Press.

Lewis, M. (2011) The Big Short: Inside the Doomsday Machine. New York, NY: W.W. Norton \& Co. Leyshon, A, and Thrift, N. (1997) Money/Space: Geographies of Monetary Transformation. London: Routledge.

Leyshon, A, and Thrift, N. (2007) The capitalization of almost everything: The future of finance and capitalism. Theory, Culture \& Society, 24(7-8): 97-115.

Lobo-Guerrero, L. (2016) Insuring Life: Value, Security and Risk. London: Routledge.

MacKenzie, D. (2007) The material production of virtuality: Innovation, cultural geography and facticity in derivatives markets. Economy and Society, 36(3): 355-76.

MacKenzie, D. (2011) The credit crisis as a problem in the sociology of knowledge. American Journal of Sociology, 116(6): 1778-841.

Martin, R. (2007) An Empire of Indifference: American War and the Financial Logic of Risk Management. Durham, NC: Duke University Press.

Mitchell, T. (2014) How the future entered government. Critical Inquiry, 40(4): 479-507. 
Montgomerie, J. and Williams, K. (2009) Financialized capitalism: After the crisis and beyond neoliberalism. Competition \& Change, 13(2): 99-107.

Opitz, S. and Tellmann, U. (2014) Future emergencies: Temporal politics in law and economy. Theory, Culture \& Society, 32(2): 107-29.

Pryke, M. and Allen, J. (2017) Financialising urban water infrastructure: Extracting local value, distributing value globally. Urban Studies, FirstView: 1-21.

Seabrooke, L. and Wigan, D. (2017) The governance of global wealth chains. Review of International Political Economy, 24(1): 1-29.

Stritzel, H. (2011) Security, the translation. Security Dialogue, 42(4-5): 343-55.

Tellmann, U. (2018) Life and Money: The Genealogy of the Liberal Economy and the Displacement of Politics. New York, NY: Columbia University Press.

Waever, O. (2011) Politics, security, theory. Security Dialogue, 42(4-5): 465-80.

Williams, M.C. (2003) Words, images, enemies: Securitization and international politics. International Studies Quarterly, 47(4): 511-31. 